\title{
Urdimento
}

Revista de Estudos em Artes Cênicas

E-ISSN: 2358.6958

\section{O teatro do Nordeste antes e depois da descida triunfal ao Rio de Janeiro}

Magela Lima

Para citar este artigo:

LIMA, Magela. O teatro do Nordeste antes e depois da descida triunfal ao Rio de Janeiro. Urdimento, Florianópolis, v. 2, n. 38, ago./set. 2020.

DOI: http:/dx.doi.org/10.5965/14145731023820200034

Este artigo passou pelo Plagiarism Detection Software | iThenticate 
Magela Lima ${ }^{1}$

\title{
Resumo
}

Considerando a história do "teatro do Nordeste", nos termos em que Paschoal Carlos Magno vai reconhecer e legitimar a poética introduzida pelo Teatro do Estudante de Pernambuco na década de 1940, este artigo recupera e lança luz sobre os encontros que o movimento teatral organizado a partir do Recife estabeleceu com os palcos do Rio de Janeiro, então tido como centro da cultura teatral do país. Particularmente, interessa aqui evidenciar as especificidades da participação da montagem de o Auto da Compadecida na primeira edição do Festival de Amadores Nacionais em 1957 para o contexto de afirmação das estratégias de visibilidade que demarcaram o Nordeste como lugar no teatro brasileiro.

Palavras-chave: Teatro do Nordeste. Teatro brasileiro. História. Cultura nacional. Auto da Compadecida.

The theater of the Brazilian Northeast before and after the triumphal descent to Rio de Janeiro

\begin{abstract}
Considering the history of the theater of the Brazilian Northeast, in the terms in which Paschoal Carlos Magno will recognize the poetics introduced by the Teatro do Estudante de Pernambuco in the 1940s, this article sheds light on the encounters that the theatrical movement from Recife established with the stages of Rio de Janeiro, considered the center of the country's theatrical culture. In particular, it is interesting here to highlight the specificities of the participation of the Auto da Compadecida in the first edition of the Festival de Amadores Nacionais in 1957 for the context of affirming the visibility strategies that marked the Northeast as a place in Brazilian theater.
\end{abstract}

Keywords: Theater of the Brazilian Northeast. Brazilian theater. History. National culture. Auto da Compadecida.

Doutor em Artes Cênicas pela Universidade Federal da Bahia. Integra o corpo docente dos cursos de Jornalismo e Publicidade e Propaganda do Centro Universitário 7 de Setembro (UNI7). lima.magela@gmail.com 
O "teatro do Nordeste" nasce no Rio de Janeiro. Se não a cena, a alcunha. É Paschoal Carlos Magno (1906-1980), segundo Luiz Maurício Britto Carvalheira (1986, p. 212), quem crava a expressão. A primeira referência data de 1948. Mais precisamente, está na edição de 22 de setembro do jornal Correio da Manhã. Paschoal, recém-chegado de mais uma viagem ao Recife, registra, então, o entusiasmo e a coragem de um punhado de moços liderados por Hermilo Borba Filho (1917-1976), que, em seu entendimento, "preocupavam-se em 'criar' através do teatro uma valorização do homem e da terra do Nordeste", e profetiza:

Não me espantarei que, em breve, se comece a falar no "teatro do Nordeste", quando se fizer a história da ação do Teatro do Estudante de Pernambuco apresentando autores, atores, cenógrafos e músicos intérpretes dos sentimentos e costumes dessa região brasileira.

Na leitura de Luís Augusto da Veiga Pessoa Reis (2008, p.23), surgia ali um rótulo, uma classificação advinda de fora para dentro, de pronto, acatada, como estratégia de penetração nos espaços centrais da cultura nacional. De todo modo, é forçoso reconhecer que aquilo que o carioca Paschoal Carlos Magno nomeia, naquele momento, decorria de um movimento já bastante organizado em termos de projeto poético no contexto da cultura teatral pernambucana. É fato que o compromisso com o Nordeste vinha pautando o trabalho do Teatro do Estudante, particularmente, desde que Hermilo Borba Filho se associou ao conjunto.

Quando de sua estreia como diretor do TEP², em 13 abril de 1946, antes mesmo de o coletivo mostrar suas criações sobre um palco improvisado na biblioteca da Faculdade de Direito do Recife, Hermilo desenvolve uma nova leitura de Teatro, Arte do Povo, manifesto apresentado originalmente em 28 de setembro de 1945, durante a II Semana de Cultura Nacional, realizada no Gabinete Português de Leitura de Pernambuco, com o intuito de reforçar que aquele grupo de teatro tinha pretensões e preocupações além do próprio fazer teatral.

O que o Teatro do Estudante pretende é realizar a redemocratização da

2 A primeira produção assinada por Hermilo Borba Filho para o grupo foi composta por duas pequenas peças: O Urso, do russo Anton Tchekhov (1860-1904), e O Segredo, do espanhol Ramon J. Sender (1901-1982). 
arte cênica brasileira, partindo do princípio de que, sendo o teatro uma arte do povo, deve aproximar-se mais dos habitantes dos subúrbios, da população que não pode pagar uma entrada cara nas casas de espetáculos e que é apática por sua natureza, de onde se deduz que os proveitos em benefício da arte dramática serão maiores levando-se o teatro ao povo em vez de trazer o povo ao teatro. (Borba Filho, 1947, p. 5).

Com o TEP, Hermilo dizia desejar a descoberta de um teatro profundamente popular e genuinamente brasileiro. Ele sonhava com uma experiência capaz de atuar sobre o público com a mesma exaltação provocada pelo carnaval e pelo futebol. Para tanto, ele defendia que se buscassem os temas nos assuntos do povo. No caso específico do Teatro do Estudante de Pernambuco, que se buscassem os temas nos assuntos do povo do Nordeste.

Todo o Nordeste é um drama de primeira grandeza, com a tragédia das secas, a escravidão do açúcar e o cangaceirismo. É o povo sofrendo, é o povo sendo explorado, é o povo lutando. São dramas do povo, que a ele interessam, que ele compreende. É poesia viva. (Borba Filho, 1947, p. 9).

Como diria Durval Muniz de Albuquerque Júnior (2001, p. 23), com o grupo, Hermilo vai promover uma nova distribuição espacial dos sentidos. A um só tempo, ele pauta uma reforma do fazer teatral vigente e, com isso ou para isso, instaura um conjunto de preocupações que acabam por reorientar o entendimento do que seria o Nordeste e o próprio teatro nordestino. Assim, sem a experiência de Hermilo Borba Filho junto ao Teatro do Estudante de Pernambuco, Paschoal Carlos Magno, talvez, ficasse sem ter o que batizar por "teatro do Nordeste".

É que o pensamento que Hermilo Borba Filho articula para o grupo pauta um programa, uma retórica, um procedimento, mesmo implícito, para o exercício da atividade artística, que diz respeito à criação ainda por fazer. É Hermilo quem traduz em termos normativos e operativos como deve proceder o artista interessado em desenvolver um Nordeste a partir do teatro ou para o teatro. Muito atuante entre 1946 e 1952, o TEP vai fundar um lugar para o Nordeste no panorama teatral, ao passo que define o próprio Nordeste enquanto lugar. A partir das teses do coletivo, originalmente formado em 1940, a identidade nordestina, naquilo que 
tem de ponto de vista a ser assumido, de uma clara tomada de posição, passa a guiar as mais variadas realizações cênicas.

O vasto programa proposto por Hermilo Borba Filho para o Teatro do Estudante de Pernambuco, pactuado com Paschoal Carlos Magno desde a primeira hora, foi sendo, aos poucos, posto em prática. Ainda em 1946, o TEP leva, gratuitamente, as montagens de O Urso e O Segredo para pátios de fábricas, praças públicas, presídios, conventos e sanatórios. Naquele ano, lança seu pioneiro concurso de peças ${ }^{3}$. Em 1947, estreia A sapateira prodigiosa, do espanhol Federico García Lorca (1898-1936), e passa a promover encontros para discutir as formas populares de representação. Em 1948, o TEP, enfim, inaugura, no Parque 13 de Maio, no Recife, A Barraca, considerada a primeira tentativa de um teatro ambulante no Brasil.

A estreia do projeto combinava música e teatro. Entre as peças apresentadas, destacam-se Cantam as harpas de Sião, reescrita posteriormente com o título de O desertor de princesa, de Ariano Suassuna, com direção de Hermilo Borba Filho; e Haja pau, de José de Moraes Pinho, encenada com bonecos de Januário de Oliveira (1910-1977), popularmente conhecido como Mestre Ginu, sob orientação de Aloísio Magalhães (1927-1982). Tão defendido quanto adiado pelos integrantes do TEP, o lançamento de A Barraca teve grande repercussão no Recife. Jornais da época dão conta de um público de 3000 espectadores. Entre eles, Paschoal Carlos Magno.

Não, não era a primeira vez que Paschoal via os integrantes do Teatro do Estudante de Pernambuco em cena. Era, no entanto, a primeira vez que ele via as orientações que Hermilo incorporou ao conjunto atuando de forma orquestrada. A inauguração de A Barraca alinhava a radicalização do desejo de levar o teatro ao povo ao propósito de revelar e despertar novas vocações dramatúrgicas

Divulgado originalmente em setembro de 1946, o Concurso de Peças do Teatro do Estudante só apresenta o resultado final em janeiro de 1948. A comissão julgadora, composta por Gilberto Freyre (1900-1987), Álvaro Lins (1912-1970), Luís Delgado (1906-1974) e Valdemar de Oliveira (1900-1977), além do próprio Hermilo Borba Filho, apontou em primeiro lugar o texto de Uma mulher vestida de Sol, de Ariano Suassuna (1927-2014). Completavam a lista: em segundo lugar, José de Moraes Pinho (1921-2014), com O poço; e, empatados na terceira colocação, Vanildo Campos Bezerra Cavalcanti (1919-1988), com Primavera, e José Ruy Barbosa, com A volante. 
comprometidas com os motivos humanos e telúricos regionais do Brasil. Assim, a noite do dia 18 de setembro revelou a Paschoal um TEP em sua plenitude. O que ele viu, então, é o que passa a chamar de "teatro do Nordeste". Ainda no Recife, Paschoal colabora com a coluna do jornalista Júlio Barbosa, o J. B., no tradicional Diário do Pernambuco, em texto publicado em 22 de setembro, e afirma: "Neste palco improvisado, o senhor Hermilo Borba Filho, como diretor, criou um milagre”.

Aos poucos, o teatro mobilizado pelo TEP vai demarcando seu espaço no panorama local e conquistando visibilidade fora do Recife. Pernambucano, o teatro do TEP passava a ser nordestino e, também, brasileiro. A proximidade do conjunto com Paschoal Carlos Magno mantinha constante especulações sobre possíveis montagens dos textos que ajudou a fomentar por grupos profissionais do Rio de Janeiro. Em 1949, a notícia, finalmente, veio a se confirmar. O Teatro Experimental do Negro (TEN) anunciava a encenação de Filhos de Santo, texto de José de Moraes Pinho4. "O assunto é dos mais palpitantes pela significação que o envolve, pois se trata nada mais nada menos do que o lançamento do teatro do Nordeste na capital do país", pontua J. B., no Diário do Pernambuco de 22 de fevereiro daquele ano.

No mesmo dia, o jornal registrava ainda as impressões do próprio José de Moraes Pinho diante da oportunidade:

Naturalmente - por que negá-lo? - estou bastante ansioso, um pouco preocupado mesmo com o fato. Entretanto, não do modo por que alguns possam pensar: com vaidade arranhada por ir ser representado no Rio. Longe de mim tal ideia. Minha preocupação gira em torno do nome teatral de Pernambuco. Não sou eu quem vai apresentar um trabalho na capital do país. Filhos de Santo é uma peça pernambucana e, como bom pernambucano, espero que vença. Porque se isso se verificar não serei eu o vencedor, porém a terra que me viu nascer. Espero ter correspondido aos fins a que nos propomos: fazer um teatro 100\% nordestino, com o aproveitamento do material inesgotável de que dispomos. Estamos, ainda no terreno das experiências e toda experiência é perigosa, muito embora resultem da maioria os melhores proveitos. Acredito na vitória de minha peça, porque se não tivesse valor Abdias Nascimento não exporia o nome de seu conjunto para apresentar um

\footnotetext{
${ }^{4}$ Quando da divulgação do resultado do concurso de peças do TEP, Ariano Suassuna, em entrevista ao jornal Correio da Manhã de 11 de março de 1948, já comentava a respeito: "O Nordeste é uma terra poderosa. Quem nasce lá guarda até a morte a sua marca inconfundível, no amor à terra, nos grandes temas trágicos da luta do homem com a seca e com o sol. [...] O Nordeste ainda tem o que dar. Os nossos temas começam a ser explorados. José de Moraes Pinho escreveu sobre Xangô uma peça negra Filhos de Santo que se montada pelo Teatro Experimental do Negro ou outra companhia seria um sucesso".
} 
trabalho nulo. Mesmo assim, aguardo, ainda, a encenação da peça e o pronunciamento da crítica. Desta, com seu senso agudo, colherei as indicações para prosseguir. Por enquanto, estou apenas ansioso para ver minha peça representada no Rio, menos por mim do que por minha terra. (Diário do Pernambuco, 22 fev. 1949).

Com direção de Abdias Nascimento (1914-2011), Filhos de Santo é o décimo espetáculo produzido pelo TEN, que completava, naquele momento, cinco anos de atuação. Considerando, no entanto, o propósito de estimular a criação de uma dramaturgia de negros entre autores brasileiros, conforme observa Miriam Garcia Mendes (1993, p.50), a peça se insere em fase mais recente da companhia, se associando, assim, às experiências de O Filho Pródigo, de autoria do mineiro Lúcio Cardoso (1913-1968), e de Aruanda, do carioca Joaquim Ribeiro (1907-1964), encenadas respectivamente em 1946 e 1947.

Bastante festejada por seus pares no Recife, a estreia de José de Moraes Pinho no Rio de Janeiro não repercute bem. Até mesmo Paschoal Carlos Magno vê com ressalvas o texto e sua montagem inaugural e se manifesta a respeito na edição de 3 de abril de 1949 do jornal Correio da Manhã.

Se disser que gostei da peça toda, dos três atos do senhor José de Moraes Pinho, Filhos de Santo, estreada segunda-feira última, pelo Teatro Experimental do Negro, no Regina, estaria mentindo. Gostei, é verdade, de algumas de suas passagens e admirei a naturalidade dos diálogos. Seu autor sabe manejar imagens e ornatos, com fluência. Falta-lhe ainda experiência para conduzir as situações dramáticas que inventa e, ao mesmo tempo, depois de haver impressionado com elas, não repeti-las, para não fadigar o espectador. Se sua intenção foi combater os malefícios de certas crendices e superstições, andou errado, no entretanto, ao deixar Pai Roque, incólume. Depois de todos os seus atos, os mais vis, nada o alcança, nem a justiça terrena nem a dos poderes sobrenaturais, como se de fato tivesse o 'corpo fechado'. [...] Não se pode negar a poesia de certas passagens e a beleza amargurada de alguns dos personagens, principalmente o da pobre mãe, que o 'pai santo' domina e subjuga. [...] Talvez um diretor com mais experiência obtivesse, com um tempo mais acelerado, um rendimento maior da história que o senhor José Moraes Pinho nos conta. [...] O senhor Abdias Nascimento [...] não pode ensinar como representar, quando de lições nesse terreno também anda precisando. [...] Salvou-nos, porém, do naufrágio de Filhos de Santo, a senhora Ruth de Souza5.

5 Integrante do núcleo fundador do Teatro Experimental do Negro, Ruth Pinto de Souza (1921-2019) 
A esse respeito, Walter Lima Torres Neto (2016, p. 265) argumenta que, no teatro, o sucesso e o fracasso são como que faces de uma mesma moeda: o reconhecimento. "São duas atitudes que indicam a troca de valores entre o individual e o coletivo e refletem as reações de grupos sociais distintos frente à obra cênica”, sustenta. Nesse sentido, é preciso registrar que a recepção negativa à estreia de Filhos de Santo, a recepção negativa ao "lançamento do teatro do Nordeste na capital do país", não tem um efeito imediato na trajetória de José de Moraes Pinho. No Recife, ele continua sendo um dramaturgo promissor, especializando-se em textos para o teatro infantil e para o teatro de animação. Coletivamente, a experiência pouco exitosa de Moraes Pinho junto ao público e à crítica especializada no Rio de Janeiro também demonstra pouco impacto.

Ainda no primeiro semestre de 1949, por exemplo, o Teatro do Estudante de Pernambuco, numa colaboração com o cenógrafo Martim Gonçalves (1919-1973), pernambucano radicado no Rio de Janeiro, encena Édipo Rei, de Sófocles (497406 a.C.), com direção de Hermilo Borba Filho. Naquele mesmo ano, o TEP estreia Quando despertamos dentre os mortos, de Henrik Ibsen (1828-1906), novamente com Hermilo na direção. Em 1950, ele acumula as funções de autor, ator e diretor na montagem de O vento do mundo. Também em 1950, Ariano Suassuna e José de Moraes Pinho são destaque no concurso de peças promovido pela Secretaria de Educação e Cultura de Pernambuco com os textos de Auto de João da Cruz e Cabeça Pelada, conquistando, respectivamente, a primeira e a segunda colocação.

Em 1951, o Teatro do Estudante de Pernambuco apresenta Otelo. Era a primeira montagem de uma peça de William Shakespeare (1564-1616) no Recife e a derradeira colaboração de Hermilo com o conjunto. Em 1952, em seu último ano de atuação, o Teatro do Estudante de Pernambuco, num esforço de Genivaldo Wanderley, ator de destaque em várias montagens do grupo, leva aos palcos $A$ cabra cabriola, de Hermilo Borba Filho, Mãe da Lua, de José de Moraes Pinho, e Caipora, de autoria do próprio Wanderley. Por fim, com direção do colombiano Enrique Buenaventura (1925-2003), o TEP estreia Três cavalheiros a rigor, texto

notabilizou-se como uma das primeiras artistas negras a fixar carreira profissional nos palcos. Estreia como atriz aos 24 anos na peça O Imperador Jones, de 1945. 
também de Hermilo, concluindo, assim, uma trajetória de pouco mais de 10 anos $^{6}$.

Coincidentemente, em 1952, o "teatro do Nordeste" experimenta mais um encontro com os palcos do Rio de Janeiro. Escrita ainda em 1947, João sem terra, de Hermilo Borba Filho, em montagem com direção de José Maria Monteiro (19232010), inaugura os trabalhos do Teatro Duse, mais uma iniciativa encabeçada por Paschoal Carlos Magno?. Quiçá, a mais importante delas. Diego Molina (2015, p. 55) explica que o Teatro Duse, autodenominado como "primeiro teatro-laboratório do Brasil", funcionando como espaço de apresentação e discussão de novas dramaturgias nacionais, pode ser compreendido como empreendimento de afirmação, continuação e, sobretudo, consolidação de práticas modernas no país. Arrematando, dessa forma, um percurso iniciado por Paschoal Carlos Magno ainda em 1938 com a criação do Teatro do Estudante do Brasil (TEB).

O Teatro Duse é aberto oficialmente junto com o seu mais importante evento, o Festival do Autor Novo, que promoveu, em cinco temporadas, até 1956, a produção de 26 espetáculos a partir de textos nacionais inéditos. Além de Hermilo Borba Filho, Aristóteles Soares (1910-1989), autor também comprometido com as teses do Teatro do Estudante de Pernambuco, embora não ligado diretamente ao conjunto, compõe a programação de estreia com Terra Queimadå. Segunda montagem do Teatro Duse, a peça contou com direção do próprio Paschoal Carlos Magno, que acabou, pela experiência, recebendo o prêmio de diretor revelação daquele ano, concedido pela Associação Brasileira de Críticos Teatrais.

A presença expressiva de peças escritas por dramaturgos nordestinos, cujas

6 O fim do Teatro do Estudante de Pernambuco é explicado por um somatório de fatores. Luiz Maurício Britto Carvalheira (1986, p.204) afirma, por exemplo, que o ano de "1950 marca o início do esvaziamento do TEP". Muito vinculado à Faculdade de Direito do Recife, o grupo, segundo ele, se fragiliza quando das formaturas de nomes como Hermilo Borba Filho, Ariano Suassuna e Aloísio Magalhães. Joel Pontes (1966, p.80), a seu tempo, aponta questões financeiras, a "pobreza asfixiante" da companhia, que pressionou o TEP a rever seu programa de dar teatro de graça ao povo; além de aspectos estéticos, como a valorização de uma dramaturgia regionalista, que nunca foi capaz de estimular novas adesões ao grupo reunido em 1946.

Ao comentar a inauguração de A Barraca pelo Teatro do Estudante de Pernambuco, Paschoal Carlos Magno, em sua coluna publicada no jornal Correio da Manhã de 26 de setembro de 1948, se referia a Hermilo Borba Filho como "o grande dramaturgo de João sem terra, que o Teatro Duse, do Seminário de Arte Dramática, representará no começo de 1949”.

8 Texto escrito em 1950, Terra Queimada foiencenado naquele mesmo ano no Recife, com direção de Jacques Gonçalves (1915-1996), inaugurando as atividades do Grupo Teatral do Atlético Clube de Amadores. 
ações se desenvolvem no Nordeste, no programa de inauguração do Teatro Duse, chama atenção. O recorte acaba por provocar comparações. A ponto de, passadas as apresentações de João sem terra e Terra Queimada, conforme registra Diego Molina (2015, p. 120), Martim Gonçalves, em artigo publicado na edição de 9 de novembro de 1952 do carioca O Jornal, reclamar: "Os autores nordestinos andam a procura de uma fórmula, de um estilo". Então, Hermilo Borba Filho e Aristóteles Soares foram muito criticados pelo "excesso de literatura" e "falsa poética" de suas obras. De todo modo, com eles, o chamado "teatro do Nordeste" dá mais um importante passo em seu projeto de nacionalização.

Já em 1953, a dramaturgia de Aristóteles Soares volta ao Rio de Janeiro. Desta vez, com Sangue Velho, peça com direção de Valdemar de Oliveira, destaque no repertório que o Teatro de Amadores de Pernambuco (TAP) reuniu para sua primeira temporada na capital do país ${ }^{9}$. Antes disso, o conjunto havia realizado excursões a Natal e Fortaleza, em 1941, Salvador, em 1944, e Maceió, em 1946. Fundado em 1941, o TAP, logo em seus primeiros anos de atividade, como destaca Décio de Almeida Prado (2003, p. 78), torna-se referência da cena pernambucana: "Um exemplo único de junção entre o desinteresse amador e as responsabilidades econômicas do profissionalismo". Mesmo sem abandonar o viés de ecletismo de sua produção, nem tampouco renegar o regime de temporadas esporádicas, diz Almeida Prado, deve-se ao grupo a introdução do teatro moderno em Pernambuco.

Para a série de apresentações no Rio de Janeiro, o Teatro de Amadores programou outros quatro espetáculos: A Casa de Bernarda Alba, do espanhol García Lorca, estreia de 1948 da companhia; Esquina Perigosa, do inglês J. B. Priestley (1894-1984), de 1949; Arsênico e Alfazema, do norte-americano Joseph Kesselring (1902-1967), de 1950; e A Primeira Legião, do também norte-americano Emmet Lavery (1902-2986), de 1952, que não chegou a ser apresentado por falta de tempo. Com exceção de Esquina Perigosa e A Primeira Legião, que contaram com encenação dos poloneses Zbigniew Ziembinski (1908-1978) e Jorge Kossowski

9 Sangue Velho estreia no Recife em 4 de abril de 1952 com apresentações no Teatro Santa Isabel. Originalmente escrita com o título de As Árvores, a peça sofre várias modificações ao longo do processo de montagem pelo Teatro de Amadores de Pernambuco, a ponto de Valdemar de Oliveira, responsável pela encenação, passar a assinar como coautor do texto. 
(1889-1969), todos os demais espetáculos tinham direção de Valdemar de Oliveira.

Com 11 anos de atividade naquele período, O TAP havia experimentado a dramaturgia de 33 diferentes autores, em sua grande maioria, estrangeiros. Até ali, apenas cinco brasileiros tinham sido encenados pelo conjunto. Dois destes, pernambucanos: Valdemar de Oliveira, grande mentor do grupo, com Um século de glória, de 1950, peça especialmente escrita em homenagem ao primeiro centenário do Teatro Santa Isabel; e Aristóteles Soares, com o "drama sertanejo" Sangue Velho, dois anos depois, coincidindo com sua participação no Festival do Autor Novo. Tão afeito a textos universais, o TAP, em seu propósito de divertir as elites, enfim, se rendia à força do teatro de cunho regionalista, parecendo aderir ao chamado "teatro do Nordeste", grande trunfo poético do Teatro do Estudante de Pernambuco. Muito embora, como afirma Joel Pontes (1966, p. 68), a linha de ação do TAP fosse diametralmente oposta a tudo quanto Hermilo Borba Filho pensasse na ocasião.

Durval Muniz de Albuquerque Júnior (2001, p. 106) observa, a esse respeito, que, no contexto brasileiro, o único regionalismo que vai conseguir efetivamente ultrapassar fronteiras e estabelecer um sentido nacional é o regionalismo nordestino. O Nordeste, espaço inventado pela ciência, pela política e também pelas artes, é, para ele, a mais bem-sucedida estratégia de elaboração imagéticodiscursiva regional do Brasil, tendo em vista seu poder de impregnação e reatualização. Possuir uma cultura própria, manifestação de sua verdade, é a base da afirmação, pontua Albuquerque Júnior, que a linguagem constrói na forma de expressão. Com isso, o Nordeste existe na exata medida em que emerge uma produção capaz de afirmar uma identidade na vinculação de obras e autores com o espaço que quer representar.

Sob a pena de se cometer anacronismos e reduzir o Nordeste a um recorte geográfico naturalizado, é preciso assumir a historicidade das práticas e dos discursos regionalizantes que ajudaram, ao longo do tempo, a sedimentar uma ideia de Nordeste enquanto região. Sem dúvida, um recorte, mas, sobretudo, um recorte sociocultural. Esse Nordeste, considera Durval Muniz de Albuquerque Júnior (2001, p. 307), nada mais é que a regularidade de certos temas, imagens, 
falas, que vão se repetir em diferentes discursos e plataformas. Não existe, sustenta, um modo de ser nordestino ou um estilo brasileiro. O que não significa dizer que a nação e a região não tenham existência real. Elas, ao contrário, se materializam em cada atitude, em cada comportamento, em cada discurso feito em nome delas. A nação e a região existem enquanto linguagem, na teia de poderes que atravessa e na rede de saberes a que se vincula.

O Nordeste existe na história. Existe naquilo que Michel de Certeau (2013, p. 6) define como "historicidade da história": o que, por um lado, remete a uma prática, e, por outro, organiza e encerra um modo de inteligibilidade. Dessa organização, diz Certeau (2013, p. 19), decorre a instauração dos atos históricos, as demarcações temporais, cujas funções especificam a incessante confrontação entre passado e presente, entre aquilo que articulou sentido à vida e aquilo que permite pensá-la. Cabe à história, pois, fazer o passado frequentar o presente. Cabe à história, como atenta Raimundo Matos de Leão (2006, p. 140), fazer ainda presente o passado, realçando a polifonia do tempo social, do tempo cultural, que pulsa na superfície dos eventos capaz de fixar a força e a resistência de determinadas datas, personagens e ações.

A histórica turnê de 1953 do Teatro de Amadores de Pernambuco no Rio de Janeiro expressa bem todo esse movimento. A imprensa carioca é muito elogiosa diante do repertório apresentado pelo TAP. Paschoal Carlos Magno, por exemplo, abre espaço para o grupo por diversas vezes em sua coluna no Correio da Manhã. Logo após a estreia, na edição de 4 de janeiro de 1953, afirma: "Criticar? Mas criticar o quê? ". "Esse grupo que nos vem do Norte $^{10}$, não honra só Pernambuco, mas o teatro do Brasil em geral. Sobra-lhe dignidade artística", pontua. No fim do mês,

10 Segundo Durval Muniz de Albuquerque Júnior (2001, p.68), nas primeiras décadas do século XX, os termos Norte e Nordeste ainda se faziam sinônimos, apesar dos sinais já bem claros de mudança. A antiga oposição Norte versus Sul, que mapeava o país desde o período colonial, aos poucos, ficava obsoleta. Uma nova sensibilidade social em relação à nação, destaca Albuquerque Júnior, vai possibilitar a reelaboração de imagens e enunciados e consolidar uma ideia organizada de Nordeste: o Norte apartado do Norte amazônico. A República consolida estruturas que contribuem de forma decisiva para o novo entendimento. Já na Constituição de 1891, a primeira do novo regime, o artigo 5o obrigava a União a destinar verbas especiais para o socorro de áreas vitimadas por flagelos naturais, abrangendo aí as secas. Em 1909, durante a breve gestão do fluminense Nilo Peçanha (1867-1924), é criado o Instituto de Obras contra as Secas (IOCS), primeira instituição pública brasileira com foco de atuação na futura região. Anos depois, no governo do paraibano Epitácio Pessoa (1865-1942), presidente entre 1919 e 1922, destacou-se oficialmente, do território do antigo Norte, a área sujeita aos periódicos percalços da seca, surgindo, assim, um novo recorte regional: o Nordeste brasileiro. 
em novo texto, publicado em 30 de janeiro, Paschoal, preocupado que era com a construção de uma identidade nacional por meio do teatro, conforme evidencia Diego Molina (2015, p. 109), lamenta o encerramento da temporada do TAP e destaca: "Raras vezes um conjunto obteve entre nós um triunfo igual. Triunfo não só de crítica como de plateia. Uma unanimidade merecida, de louvor. Deu-nos quatro espetáculos admiravelmente bem interpretados, encenados e dirigidos”.

Paschoal Carlos Magno registra ainda a performance do elenco feminino, ressaltando, em especial, o trabalho das atrizes Diná da Rosa Borges de Oliveira (1907-1998), Margarida Cardoso e Geninha de Sá da Rosa Borges; aponta um valor excepcional nas três direções de Valdemar de Oliveira, não tendo este, ao contrário de Ziembinski, frequentado academias de arte dramática; e festeja o encontro do TAP com Aristóteles Soares, que considera um expoente do que tinha por "teatro do Nordeste", "uma nova geração de dramaturgos de olhos voltados para sua gente e seu meio"11. Sangue Velho, no entender de Paschoal Carlos Magno, é "uma verdadeira peça regional”. Tese endossada também por Valdemar de Oliveira, que, acerca da escolha do texto de Aristóteles Soares para a temporada no Rio de Janeiro, declarou, em entrevista ao Diário de Pernambuco de 17 de janeiro de 1953: "Não vamos mostrar, apenas, uma peça brasileira. Para nós, ela representa mais do que isso: é uma peça pernambucana, com o cheiro vivo do sertão nordestino".

Ainda em 1953, Aristóteles Soares protagoniza mais um importante ato para aquela geração de artistas. Então, o Serviço Nacional de Teatro (SNT) publica Terra Queimada como parte da Coleção Dionysos de Teatro. A impressão de uma obra, observa Jean-Pierre Ryngaert (1996, p. 24), é importante por significar uma oportunidade de circulação e apreciação independente da representação. Em 1954, é a vez Aristóteles Soares, também por Terra Queimada, receber o prêmio Artur Azevedo, da Academia Brasileira de Letras. A projeção nacional do autor anima

\footnotetext{
11 No Recife, associação semelhante foi feita por Hermilo Borba Filho, quando da estreia do espetáculo. Sobre Sangue Velho, ele escreveu para o Diário de Pernambuco, em coluna publicada na edição de 6 de abril de 1952: "Sexta-feira, à noite, no Santa Isabel, houve um acontecimento extraordinário: o lançamento, pelo Teatro de Amadores de Pernambuco, da peça do senhor Aristóteles Soares (colaboração do senhor Valdemar de Oliveira), Sangue Velho. Acontecimento, sem dúvida, da maior significação, pois nesse espetáculo aliaram-se o potencial artístico do conjunto à boa qualidade da obra, dando-se um largo passo à frente no sentido de fortalecer o teatro do Nordeste, talvez o movimento de maior significação na vida cultural-dramática do país".
} 
diferentes montagens de suas peças no Recife em meio a um período de grande efervescência de agremiações amadoras formadas por estudantes na capital pernambucana. O Grupo Teatral do Atlético Clube de Amadores, por exemplo, o primeiro a encenar Terra Queimada, estreia, agora com direção de Clênio Wanderley (1929-1976), naquele mesmo ano, outro texto de sua autoria, o inédito A Trovoada'12.

Tendo despontado como ator do Teatro Universitário de Pernambuco (TUP), no elenco de É proibido suicidar-se na primavera, do dramaturgo espanhol Alejandro Casona (1903-1965), com direção de Walter de Oliveira (1909-1994), em 1948, Clênio Wanderley ingressa no Teatro do Estudante de Pernambuco no ano seguinte, participando das montagens de Édipo Rei, Quando despertamos entre os mortos, Otelo e Três cavalheiros a rigor. Na década de 1950, já como diretor, participa da formação de diferentes conjuntos: o Teatro da União dos Estudantes Secundários de Pernambuco, em 1952, com a peça Cana Brava, de Aristóteles Soares; o Teatro do Funcionário Público, em 1953, com a comédia Se o Guilherme fosse vivo, de A. Torrado; e o Teatro Adolescente do Recife (TAR), em 1955, com nova montagem de Terra Queimada. Ariano Suassuna, em depoimento a Leidson Ferraz (2007, p. 20), afirma que o Teatro Adolescente, grupo ao qual nunca chegou a estar de fato vinculado, veio preencher no Recife o vazio deixado desde o fim do Teatro do Estudante de Pernambuco e a ida de Hermilo Borba Filho para São Paulo.

Com este grupo, Clênio Wanderley é responsável pela primeira encenação de o Auto da Compadecida, de Ariano Suassuna, em 1956. O sucesso de o Auto da Compadecida, em sua passagem pelo Festival de Amadores Nacionais, em janeiro de 1957, em sua "descida triunfal ao Rio de Janeiro", como diz Décio de Almeida Prado (2003, p. 61), é melhor entendido se comparado, por oposição, ao fracasso do espetáculo em sua estreia no Recife, em setembro de 1956. Então, das três récitas agendadas para o tradicional Teatro Santa Isabel, a última não chegou a

\footnotetext{
12 Em 1955, A Trovoada foi selecionada para o II Festival Paulista de Teatro Amador, sendo encenada em São Paulo pelo elenco do grupo Comediantes Paulistas, com direção do pernambucano Genivaldo Wanderley. Naquela mesma edição do festival, Wanderley dirigiu o texto de outro conterrâneo, José Carlos Cavalcanti Borges (1910-1983), fundador do Teatro de Amadores de Pernambuco, que escreveu Fogo Morto a partir da obra do paraibano José Lins do Rego (1901-1957), peça apresentada pela Associação dos Servidores da Caixa Econômica Federal de São Paulo.
} 
acontecer. E o que é pior: por falta de público. Antes disso, em maio daquele mesmo ano, vale ressaltar, o texto de Ariano Suassuna já havia tido uma primeira montagem abortada na capital pernambucana.

Em 1955, escrevi o Auto da Compadecida. Tentei montar a peça com um grupo de adolescentes que dirigia então no Ginásio Pernambucano. Como não acertássemos na encenação e eu precisasse dar um espetáculo no dia do aniversário do colégio, escrevi, num só dia, uma outra peça em um ato, uma espécie de "facilitação" do terceiro ato do Auto da Compadecida, com outra história, é verdade. [...] A peça recebeu o título de O processo do Cristo negro. (Suassuna, 2005, p. 150).

Com a passagem de o Auto da Compadecida pelo primeiro Festival de Amadores Nacionais, promovido por Dulcina de Moraes (1908-1996), é estabelecido um novo paradigma ao teatro nordestino. É, pelo episódio de 1957, por exemplo, que Nélson de Araújo (1991, p. 374) começa a narrar a história do teatro no Nordeste. "Uma elaboração de autêntica matéria regional”, como define Araújo, a peça de Ariano Suassuna, segundo ele, demarca a contribuição do Nordeste ao teatro brasileiro contemporâneo. Com a ida do espetáculo do Teatro Adolescente do Recife ao Rio de Janeiro, havia, claramente, sido vencido um limite territorial. Aquele teatro deixava de ser uma prática exclusiva do Recife, ao mesmo tempo em que projetava, definitivamente, o movimento teatral pernambucano. Como recorda a atriz Socorro Rapôso, primeira intérprete da Compadecida, em entrevista a Leidson Ferraz (2007, p. 27), o Auto da Compadecida era uma experiência do tipo "daqui (do Recife) para o mundo inteiro".

O Teatro Adolescente do Recife deixa o Rio de Janeiro com os prêmios de melhor espetáculo, melhor direção para Clênio Wanderley ${ }^{13}$ e melhor atriz para Ilva Niño ${ }^{14}$ e Ariano Suassuna absolutamente festejado pela crítica, elevado à categoria

\footnotetext{
13 Além dos prêmios que conquistou por o Auto da Compadecida, Clênio Wanderley também se destacou naquela edição do Festival de Amadores Nacionais pela direção de $A$ grande estiagem, texto do pernambucano Isaac Gondim Filho (1925-2003), encenado com o elenco da Federação Baiana dos Teatros de Amadores, apontado como segundo melhor espetáculo da mostra.

${ }^{14}$ Intérprete da Mulher do Padeiro na versão original de o Auto da Compadecida, a atriz Nina Elva, Ilva Niño de carreira, estava no elenco da montagem de Terra Queimada que inaugura os trabalhos do Teatro Adolescente do Recife em março de 1956 e também participou da encenação de O processo do Cristo negro que Ariano Suassuna estreia em maio daquele mesmo ano com estudantes secundaristas.
} 
de "autor nacional". Além da apresentação na programação oficial do festival, no dia 25 de janeiro, a peça ganhou novas sessões nos dias 13 e 14 de fevereiro. 0 sucesso de o Auto da Compadecida consolida, assim, um lastro mais abrangente no campo das legimitidades ao chamado "teatro do Nordeste". O espetáculo estabelece um conjunto de relações que organizam e mantém as condições necessárias para a conservação e sobrevivência do programa deflagrado por Hermilo Borba Filho e o Teatro do Estudante de Pernambuco uma década antes.

Num país que sofre de falta de autores dramáticos, onde se luta contra a falta de teatros, a falta de atores, a falta de diretores e a falta de técnicos, onde se acende uma vela a Shakespeare e outra a Sauvajon (e uma terceira a Abílio Pereira de Almeida pela lei dos dois por um), Ariano Suassuna apareceu no horizonte nordestino como a primeira grande esperança de um teatro verdadeiramente brasileiro. Fomos todos tomados de surpresa; a autenticidade de Suassuna era estonteante; e não pudemos nos furtar à ilusão de que ele, como qualquer mágico competente, poderia tirar uma Compadecida de sua cartola cada vez que assim the aprouvesse. (Heliodora, 1958).

Apresentada mais vezes no Rio de Janeiro que no Recife, a peça ganha uma primeira adaptação em São Paulo já em março de 1957, com Hermilo Borba Filho, que lá havia se fixado desde 1953, após a extinção do TEP, dirigindo o Studio Teatral Nelson Duarte. Em julho daquele ano, o texto de Ariano Suassuna é publicado em livro pela Editora Agir. Em janeiro de 1958, o Teatro Adolescente do Recife inaugura, com temporada de o Auto da Compadecida, o Teatro Independência, em Santos, no litoral de São Paulo. Em junho, cumpre temporada no Theatro Santa Roza, em João Pessoa, na Paraíba. A peça encerra aquele ano com duas novas montagens estreando quase que ao mesmo tempo em Belo Horizonte e no Rio de Janeiro.

Em novembro, o Grêmio Literário Tristão de Athayde encena versão de o Auto da Compadecida com direção de João Etienne Filho (1918-1997) na capital mineira, seguindo depois para Ouro Preto. Em dezembro seguinte, novamente com direção de Clênio Wanderley, a peça é montada no Rio de Janeiro, a pedido de Dulcina de Moraes, ficando em cartaz por 11 meses consecutivos e promovendo mais de 470 apresentações. Então, o ator José Gonçalves foi convidado a interpretar novamente o papel de Jesus Cristo, enquanto Clênio Wanderley seguia como 
Chicó. Em março de 1959, o Auto da Compadecida chega aos palcos do interior pernambucano em versão do Teatro de Amadores de Caruaru, com direção de Luiz Mendonça, também egresso do TAR. Em maio, Martim Gonçalves monta o texto em Salvador, abrindo o ano letivo da Escola de Teatro da Bahia, em atividade desde 1956.

Em outubro, o texto ganha adaptação do recém-criado Teatro Cacilda Becker e faz apresentações no Teatro Santa Isabel, no Recife, para, em seguida, fazer sua estreia internacional, no Teatro Tivoli, de Lisboa, em Portugal. O pernambucano Octávio Catanho, o Severino de Aracaju da estreia de o Auto da Compadecida em 1956, segue no papel na encenação de 1959. É em meio à projeção de o Auto da Compadecida que Ariano Suassuna vai escrever ainda os textos de O casamento suspeitoso, que a companhia capitaneada pelos atores Nydia Lícia (1926-2015) e Sérgio Cardoso (1925-1972) estreia, com direção de Hermilo Borba Filho, em janeiro de 1958, em São Paulo; e O santo e a porca, peça que Cacilda Becker (1921-1969) vai apresentar no Rio de Janeiro a partir de março daquele mesmo ano com direção de Ziembinski.

Observados em conjunto, a série de encontros do chamado "teatro do Nordeste" com o público do Rio de Janeiro, põe uma questão em evidência: como explicar a repercussão conquistada por o Auto da Compadecida em 1957? Como diferenciar a experiência da participação do Teatro Adolescente do Recife no Festival de Amadores Nacionais do que ocorreu antes, com a montagem de Filhos de Santo, pelo Teatro Experimental do Negro, em 1949; com a seleção de João sem terra e Terra Queimada para inaugurar o Festival do Autor Novo do Teatro Duse, em 1952; e com a temporada de Sangue Velho, com o Teatro de Amadores de Pernambuco, em 1953? A noite estreia de A Barraca pelo Teatro do Estudante de Pernambuco, ainda em 1948, talvez, aponte uma resposta. Foi ali, é importante lembrar, que Paschoal Carlos Magno se deu conta da emergência de um possível "teatro do Nordeste".

Como Paschoal naquela ocasião, a plateia que acompanhou as apresentações de o Auto da Compadecida no Rio de Janeiro viu as engrenagens firmadas pelo TEP e afirmadas por outros tantos conjuntos que o seguiram no 
contexto da cultura teatral pernambucana funcionando, a um só tempo, de modo organizado e coerente. Os dois momentos, separados por quase uma década, revelam uma discreta, mas importante, revisão da tese do moderno teatro brasileiro, e também do moderno teatro pernambucano, de que a tão desejada renovação da cena decorreria do aparecimento e desenvolvimento de novos autores. A esse respeito, merece destaque um comentário de Hermilo Borba Filho registrado por Paschoal Carlos Magno em sua coluna no Correio da Manhã na edição de 26 de setembro de 1948:

O teatro brasileiro não está se desenvolvendo verdadeiramente, pois se de um lado, no que diz respeito a atores e diretores, floresce e frutifica, é como que mutilado na sua expansão concernente à formação e aparição de autores. Um teatro só é realmente nacional através de seus autores.

Cantam as harpas de Sião e Haja pau, em 1948, e o Auto da Compadecida, em 1957, não projetam, entretanto, como única e exclusiva influência a força do texto teatral. São, na verdade, o somatório de várias forças. Se não questionam, em absoluto, a supremacia da dramaturgia ou a figura do dramaturgo, dialogam mais com uma noção de encenação moderna, no sentido de, como considera Jean-Jacques Roubine (1998, p.46), propiciar o desenvolvimento de uma "arte homogênea", que equilibra a tradição de valorização do texto e a busca de novos recursos para a composição do espetáculo, permitindo a afirmação de uma semântica do palco. De tal forma, que é difícil separar, no projeto poético iniciado com o Teatro do Estudante de Pernambuco, o que é da ordem do texto e o que é da cena.

Na inauguração de A Barraca, Cantam as harpas de Sião e Haja pau e o Auto da Compadecida, na programação do Festival de Amadores Nacionais, não são, por assim dizer, exatamente, textos teatrais de Ariano Suassuna e de José de Moraes Pinho que são entregues ao público. São experiências que apontam para o que Jean-Pierre Ryngaert (1996, p.20) vai ter como exemplo de um teatro que não se interessa em afirmar a ideia de representação como prolongamento unívoco, ilustração insípida, mera tradução corporal e visual que nada de novo 
acrescenta à dramaturgia. Publicada em livro depois de a estreia pelo Teatro Adolescente do Recife, a versão impressa de o Auto da Compadecida, em sua primeira rubrica, por exemplo, vai registrar que a sugestão de organizar o espaço cênico como um picadeiro de circo trata-se de uma "ideia excelente de Clênio Wanderley." (Suassuna, 2004, p. 21).

De onde se pode concluir que o impacto da passagem de o Auto da Compadecida pelo Rio de Janeiro em 1957 não decorre de um elogio restrito à dramaturgia. Mesmo com toda celebração que, a partir de então, passa a ser dedicada à obra de Ariano Suassuna, o diferencial daquela montagem repousa, essencialmente, naquilo que ela tinha de coletivo, de experiência compartilhada, comum. Ao todo, 16 atores entravam em cena. O Teatro Adolescente do Recife reunia, em seu elenco, diferentes gerações associadas ao movimento que fundou, nos termos que Paschoal Carlos Magno vai reconhecer e legitimar, o chamado "teatro do Nordeste". Além de Ariano Suassuna, iniciado no teatro no contexto da retomada do Teatro do Estudante de Pernambuco em 1946, e Clênio Wanderley, ligado ao conjunto desde 1949, o TAR era resultado do cruzamento da apropriação e da experimentação das ideias lançadas por Hermilo Borba Filho por uma série de outros artistas.

Assim, o Teatro Adolescente do Recife aproximava egressos dos TEP, que, claramente, se recusaram a aceitar o fim do grupo, com experiências as mais distintas que ajudaram a perpetuar o espírito do Teatro do Estudante na cena pernambucana. Na montagem de o Auto da Compadecida, por exemplo, estavam os alunos de Ariano Suassuna, dentre os quais a atriz Ilva Niño; estavam nomes que despontaram nas peças que Clênio Wanderley dirigiu para o Teatro da União dos Estudantes Secundários de Pernambuco e para o Grupo Teatral do Atlético Clube de Amadores, como Luiz Mendonça e José Gonçalves; e estavam também integrantes de outros conjuntos afeitos aos "valores da terra", como o Grêmio Dramático Paroquial de Água Fria, de Octávio Catanho e José Pimentel (1934-2018), que haviam estreado em 1954 com a encenação de Lampião, da cearense Rachel de Queiroz (1910-2003).

O Auto da Compadecida do Teatro Adolescente do Recife atesta, dessa 
maneira, a expansão e assimilação das teses do TEP por um lastro maior de realizadores e de códigos da criação cênica. Era uma dramaturgia comprometida com o "teatro do Nordeste" devidamente orientada por uma encenação e também uma interpretação alinhada à mesma cartilha. No texto da peça, Ariano Suassuna (2004, p. 21-22) reitera, em diversas oportunidades, que, para a plena execução daquela dramaturgia, é fundamental observar e respeitar aspectos da cena:

O Auto da Compadecida foi escrito com base em romances e histórias populares do Nordeste ${ }^{15}$. Sua encenação deve, portanto, seguir a maior linha de simplicidade, dentro do espírito em que foi concebido e realizado.

O autor gostaria de deixar claro que seu teatro é mais aproximado dos espetáculos de circo e da tradição popular do que do teatro moderno.

Ao abrir o pano, entram todos os atores, com exceção do que vai representar Manuel ${ }^{16}$, como se se tratasse de uma tropa de saltimbancos, correndo, com gestos largos, exibindo-se ao público.

Já no manifesto Teatro, Arte do Povo, Hermilo Borba Filho (1947, p. 17) ressaltava: "Acreditamos no ator como elemento principal da arte dramática". O Auto da Compadecida do Teatro Adolescente do Recife, enfim, parece executar plenamente tal projeto, fazendo lembrar o pensamento de Lucia Calamaro (1999, p.83), para quem: "Não há cultura sem corpos, não há corpos sem práticas espetaculares”. Jean-Jacques Roubine (2002, p.43) também aproxima as ideias de corpo e lugar. Ele diz que o ator deve aprender a conhecer seu corpo como se explora um território. O corpo, segundo Roubine, é uma outra palavra. É o que, face a um espectador, reveste o ator de sua realidade carnal. É, ainda, reconhecidamente, fator determinante para o envolvimento entre palco e plateia,

${ }^{15}$ O primeiro ato é inspirado em O enterro do cachorro. É quando Ariano Suassuna introduz João Grilo e Chicó, os personagens principais, e localiza a peça no interior do Nordeste - ao fazer referência à Serra do Araripe, no Ceará, e às cidades de Taperoá, na Paraíba, sua terra natal, e Propriá, em Sergipe. Além disso, deflagra a série de pecados que marca a rotina de todos os tipos que revela. O segundo ato é baseado em $A$ história do cavalo que defecava dinheiro. Já o terceiro ato provém de o castigo da soberba, quando acontece a invocação de Nossa Senhora e o julgamento final da trama.

${ }^{16}$ Nosso Senhor Jesus Cristo. 
para a intensidade da relação teatral. O Auto da Compadecida assegura, pois, um corpo ao chamado "teatro do Nordeste", até então, muito associado ao domínio da literatura dramática.

Nesse sentido, sobressai a colaboração de Clênio Wanderley, ator e diretor da montagem de 1956. Egresso daquele processo, o ator José Pimentel (2007, p. 13) resume bem a influência de Clênio Wanderley junto ao Teatro Adolescente do Recife: "O TAR era Clênio, que 'fazia' todos os papeis. [...] Diziam: 'Parece um conjunto de Clênios no palco'”. Para Joel Pontes (1966, p. 125), o grande serviço prestado por Clênio Wanderley ao teatro pernambucano e brasileiro foi justamente iniciar atores e lançar peças e escritores. Quase sempre, privilegiando o sotaque regional que carregavam. Ao preferir a literatura da região, argumenta Pontes, o diretor conseguia simplificar possíveis problemas de caracterização de personagens, guiando seus elencos por temas e tipos de fácil alcance. Assim, conseguia uma veracidade de cena que, para muitos, podia parecer apurada elaboração artística e prodígio técnico, mas que, segundo ele, refletia mais o estado natural dos temas e intérpretes com os quais costumava trabalhar. Clênio Wanderley, em sua direção, sabia conservar a espontaneidade dos seus atores, tornando, como afirma Joel Pontes, quase impossível a distinção entre o que neles era claramente instintivo e o que foi apreendido ao longo dos ensaios.

Fato é que, com a montagem de o Auto da Compadecida, o Teatro Adolescente evidencia que, para os artistas que seguiram o movimento da década de 1940 no Recife, o Nordeste não é um tema apenas; é, sobretudo, uma forma de fazer teatro. Como tal, como um sistema organizado, um sistema simbólico, como define Pierre Bourdieu (2003, p. 9), capaz de exercer um poder de estabelecer uma ordem, de alinhar concordâncias, é que o "teatro do Nordeste" consegue se prolongar no tempo. Assim, quanto mais são repetidas, as teses que Hermilo Borba Filho introduz como novidade vão se convertendo em referência de uma criação, fixando um entendimento particular de teatro e de Nordeste. Podendo-se afirmar que, tão importante quanto o protagonismo de Hermilo junto ao Teatro do Estudante de Pernambuco, foi o compromisso com que assumiu esse programa as gerações que o seguiram. O Auto da Compadecida consolida um conjunto de 
ideias que vinham sendo gestadas e experimentadas, mesmo sem a repercussão desejada por seus principais idealizadores, ao cabo de um percurso de 10 longos anos.

Se, até ali, até a empreitada do Teatro Adolescente do Recife, o "teatro do Nordeste" era uma realização com contornos ainda pouco definidos, a projeção do texto de Ariano Suassuna e do próprio dramaturgo, da direção e de parte expressiva do elenco da primeira encenação, vão objetivar aquela poética de forma categórica. Perseguido pela seca, sempre ela, a miséria e a injustiça, o Nordeste de Ariano Suassuna vai projetar, nos palcos e nos bastidores, homens capazes de sonhar, de conviver com o maravilhoso. Terra espinhenta, parda, pobre e pedregosa, mas também de aventuras e desventuras, o Nordeste, na realidade criada pelo artista e recriada pelo TAR, tem passado, tradição e tem teatro: o teatro de bonecos, de encenações religiosas, das narrativas dos cantadores de feira, do cordel, de onde poderia surgir um estilo de representação particular, que superasse de vez as impostações e estilos importados. O que se desenrolou a partir do Teatro do Estudante de Pernambuco de 1946 em diante, sedimentava, assim, uma tradição teatral, uma cena, um lugar que nem mesmo os mapas reconheciam.

\section{Referências}

ALBUQUERQUE JÚNIOR, Durval Muniz de. A invenção do Nordeste e outras artes. São Paulo: Cortez, 2001.

ARAÚJO, Nélson de. História do teatro. Salvador: Empresa Gráfica da Bahia, 1991.

BORBA FILHO, Hermilo. Duas Conferências - Teatro: Arte do Povo / Reflexões Sôbre a "Mise-en-Scène". Recife: Diretoria de Documentação e Cultura/Prefeitura Municipal do Recife, 1947.

BOURDIEU, Pierre. O poder simbólico. Rio de Janeiro: Bretrand Brasil, 2003.

CALAMARO, Lucia. De cuerpos y viajes: notas sobre la transferencia intercultural de las formas espectaculares. In: GREINER, Crhiristine; BIÃO, Armindo (Org.). Etnocenologia: textos selecionados. São Paulo: Annablume, 1999, p. 75-83. 
CARVALHEIRA, Luiz Maurício Britto. Por um teatro do povo e da terra: Hermilo Borba Filho e o Teatro do Estudante de Pernambuco. Recife: Fundarpe, 1986.

CERTEAU, Michel de. A escrita da história. Rio de Janeiro: Forense, 2013.

FERRAZ, Leidson (Org.). Memórias da cena pernambucana - volume 3. Recife: Gráfica Santa Marta: 2007.

HELIODORA, Bárbara. A Alularia de Suassuna. Suplemento Dominical do Jornal do Brasil, Rio de Janeiro, 23 de março de 1958, p. 7.

LEÃO, Raimundo Matos de. Abertura para outra cena: o moderno teatro na Bahia. Salvador: Edufba, 2006.

LIMA, Magela. Os Nordeste e o teatro brasileiro. Jundiaí: Paco Editorial, 2019.

MENDES, Miriam Garcia. O negro e o teatro brasileiro (entre 1889 e 1982). São Paulo: Hucitec, 1993.

MOLINA, Diego. Teatro Duse: o primeiro teatro-laboratório do Brasil. Rio de Janeiro: Funarte, 2015.

NETO, Walter Lima Torres. Ensaios de cultura teatral. Jundiaí: Paco Editorial, 2016.

PIMENTEL, José. A maturidade do Teatro Adolescente do Recife. In: FERRAZ, Leidson (Org.). Memórias da cena pernambucana - volume 3. Recife: Gráfica Santa Marta: 2007, p. 12-13.

PONTES, Joel. O teatro moderno em Pernambuco. São Paulo: DESA/Coleção Buriti, 1966.

PRADO, Décio de Almeida. O teatro brasileiro moderno. São Paulo: Perspectiva, 2003.

REIS, Luís Augusto da Veiga Pessoa. Fora de cena, no palco da modernidade: um estudo do pensamento teatral de Hermilo Borba Filho. Recife, 2008. Tese (Doutorado) - Programa de Pós-Graduação em Letras, Universidade Federal de Pernambuco.

ROUBINE, Jean-Jacques. A linguagem da encenação teatral. Rio de Janeiro: Jorge Zahar, 1998.

ROUBINE, Jean-Jacques. A arte do ator. Rio de Janeiro: Jorge Zahar, 2002.

RYNGAERT, Jean-Pierre. Introdução à análise do teatro. São Paulo: Martins Fontes, 1995. 
SUASSUNA, Ariano. Auto da Compadecida. Rio de Janeiro: Agir Editora, 2004.

SUASSUNA, Ariano. A pena e a lei. Rio de Janeiro: Agir Editora, 2005.

Recebido em: 14/06/2020

Aprovado em:12/07/2020 